\title{
Tapping an unexploited repository: Carnoy's fixed cell pellets for proteomic biomarker research in leukemia
}

\author{
FERDINAND VON EGGELING, ANNETT BLEUL, IVAN F. LONCAREVIC, \\ SUSANNE MICHEL, ANITA HELLER and CHRISTIAN MELLE \\ Core Unit Chip Application (CUCA), Institute of Human Genetics and Anthropology, \\ Medical Faculty at the Friedrich Schiller University Jena, Jena, Germany
}

Received March 11, 2008; Accepted April 29, 2008

\begin{abstract}
For chromosomal analysis in tumor genetics, cells from blood and bone marrow are prepared and preserved virtually indefinitely in Carnoy's fixative (methanol/acetic acid). Numerous samples are stored unvalued in hospitals and institutes worldwide. We developed a method to analyze proteins from even a small amount of these cells by mass spectrometry using affinity chromatographic surfaces (SELDI), and demonstrated the application of proteomic biomarker research in cases of acute myeloid leukemia.
\end{abstract}

\section{Introduction}

Acute myeloid leukemia (AML) is characterized by specific cytogenetic aberrations. This leads to the assumption that the proteome also differs in its specific expression patterns and post-translational modifications $(1,2)$. Therefore, proteinbased biomarkers in blood or bone marrow cells have great potential as new diagnostic markers in hematological neoplasms. They should be able to serve as early predictive markers at initial diagnosis, help to monitor disease stage throughout therapy and allow the prediction of disease outcome.

For proteomics, blood or bone marrow can be divided into extracellular and intracellular components. The extracellular proteome consists of high-abundant serum-specific proteins such as albumin and of proteins released from cells as a result of damage, cell death or abnormal secretion. Over 10,000 different proteins with high variability have been estimated to be commonly present in plasma; their concentrations range over at least 15 orders of magnitude, including many lowabundant proteins (3). This high range hampers the analysis of low-abundant peptides or proteins. Fractionated plasma can be used for enhanced perfomance. In the case of the

Correspondence to: Dr Ferdinand von Eggeling, Core Unit Chip Application, Institute of Human Genetics and Anthropology, Klinikum der FSU Jena, D-07740 Jena, Germany

E-mail: fegg@mti.uni-jena.de

Key words: leukemia, Carnoy's fixed cell, surface-enhanced laser desorption and ionization, mass spectrometry, protein proteomic analysis of leukemias, plasma or serum offers the advantage of being usable irrespective of the percentage of blasts. The intracellular proteome, especially of leukemic cells, should be more characteristic and therefore more suitable for the identification of biomarkers for diagnosis, stratification and prognosis. Here, the number of blasts might be an important factor.

Until now, few studies using either plasma or cells have been performed. Albitar et al (4) analyzed plasma from acute lymphoblastic leukemia (ALL) patients with surface enhanced laser desorpotion/ionization (SELDI) technology and found a high prognosis for recurrence. They reported that peripheral blood plasma is adequate for the prediction of clinical behavior in patients with ALL, irrespective of the percentage of bone marrow blasts. Bone marrow cells were analyzed by different groups mainly with two-dimensional gel electrophoresis, matrix-assisted laser desorption/ionization time of flight mass spectrometry (MALDI TOF MS), SELDI and tandem MS. Balkhi et al (5) identified significant differences in the proteome and post-translational modification (PTM) of peptides between specific cytogenetic groups [e.g. PRKAC for $11 \mathrm{q} 23$ and JUN and MYC for inv(16)]. In two other studies, proteomic differences between leukemia subtypes were found $(6,7)$. Lopez-Pedrera et al (8) identified significantly altered proteins including suppressors and signal transduction mediators, which are associated with malignancy.

A well-established tool for protein profiling is SELDI technology, which can be used for the analysis of serum and cells (9). SELDI utilizes chips with affinity surface coatings to specifically retain proteins based on their physicochemical characteristics prior to TOF MS analysis. Crude protein lysates or catapulted specimens can be applied directly onto the chip surface. The desired proteins are retained on the chromatographic surface and contaminants, such as buffer salts or detergents, are washed off. Therefore, this technique is quantitative and more sensitive compared with MALDI systems $(10,11)$. In exchange, the resolution is lower, but this can be disregarded as the instrument is not primarily used for the exact measurement of peptides but rather for the comparison of two different protein lysates (e.g. normal vs. tumor tissue). SELDI can be used to complement 2-DE for biomarker research since small proteins as well as proteins with an extreme $\mathrm{pI}$ are detectable. For SELDI-MS, only a small amount of cells is needed, making the technology ideal for small cell numbers or microdissected tissue samples $(12,13)$. 


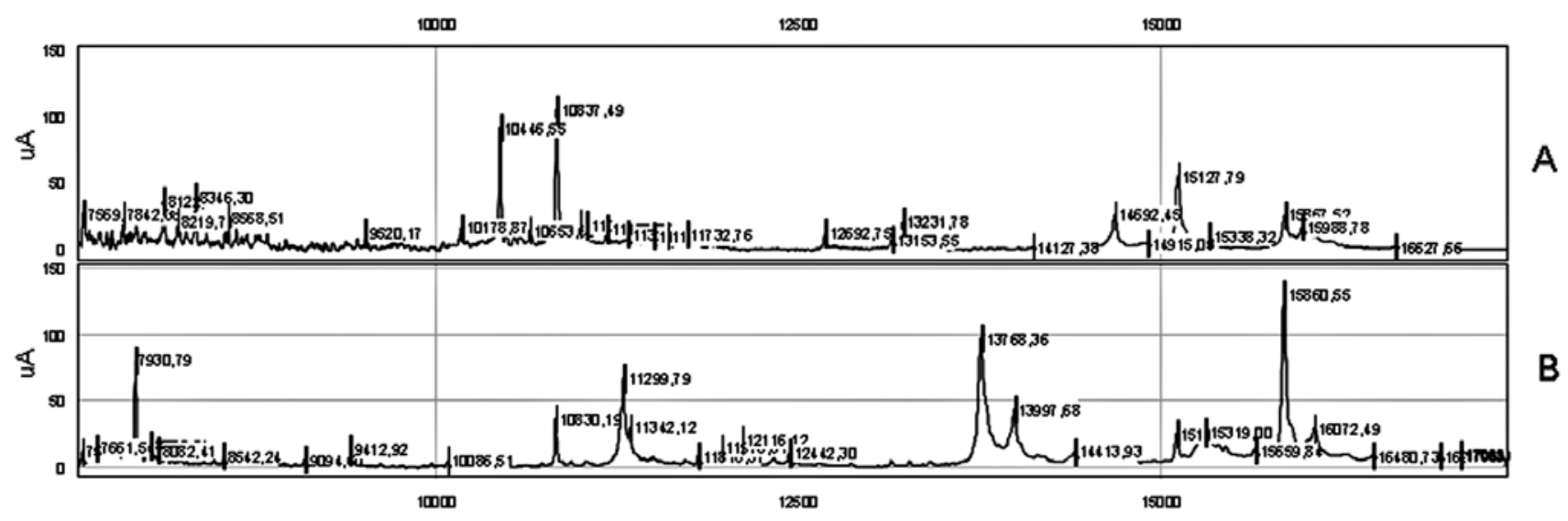

Figure 1. Representative spectra of a cell lysate from native (A) and acetic acid/methanol-fixed (B) leukemic cells.

In contrast to standard protein isolation protocols, we developed a method including cell preparation steps, activation of ProteinChip arrays and the direct application of cells.

\section{Materials and methods}

After cultivation, bone marrow cells were processed by routine cytogenetic preparation [hypotonic treatment and fixation with methanol/glacial acetic acid (1:3 v:v)] and frozen at $-20^{\circ} \mathrm{C}$ as described elsewhere (14). As a control, fresh unfixed cells were obtained by density gradient centrifugation and stored at $-80^{\circ} \mathrm{C}$. For successful analysis, we used IMAC 30 ProteinChip arrays (BioRad), but other surfaces could be used as well. Five microliters of $0.1 \mathrm{M} \mathrm{Ni}$-sulfate were applied twice to the spots and incubated for $15 \mathrm{~min}$ in a humidity chamber, then washed away with water. Five microliters of binding buffer $(0.5 \mathrm{M} \mathrm{NaCl})$ were incubated for $5 \mathrm{~min}$ and removed. Two microliters each of the fixed and untreated cells (containing 10,000 cells) were applied to one spot and dried at room temperature for $10 \mathrm{~min}$. Two microliters of lysis buffer (100 mmol/l Na-phosphate, $\mathrm{pH}$ 7.5, $5 \mathrm{mmol} / \mathrm{l}$ EDTA, $2 \mathrm{mmol} / \mathrm{l} \mathrm{MgCl}{ }_{2}, 3 \mathrm{mmol} / \mathrm{l}$ 2-ß-mercaptoethanol, $1 \mathrm{ml} \mathrm{CHAPS}$, $500 \mu \mathrm{mol} / 1$ leupeptin and $1 \mathrm{mmol} / 1$ phenylmethylsulfonyl fluoride) were added, and the chip was incubated for $10 \mathrm{~min}$ in a humidity chamber. Binding buffer $(2 \mu \mathrm{l})$ was applied, incubated for $20 \mathrm{~min}$ and removed. The spots were washed three times with the same buffer and twice with aqua demin. After drying at room temperature, $0.5 \mu 1$ sinapinic acid (saturated solution in $0.5 \%$ trifluoroacetic acid $/ 50 \%$ acetonitrile) was added twice and dried on air.

We performed mass analysis using a ProteinChip Reader [series 4000; Ciphergen (now BioRad)] according to an automated data collection protocol. Spectra were normalized with total ion current and cluster analysis of the detected signals. We selected signals between 2.5 and $20 \mathrm{kDa}$ for the low range exhibiting a signal-to-noise ratio of at least 10 , and analyzed them using the Mann-Whitney U-test for nonparametric data sets (CiphergenExpress; version 3.0).

\section{Results and Discussion}

The above protocol was applied to analyze the difference between native and methanol/glacial acetic acid fixed bone

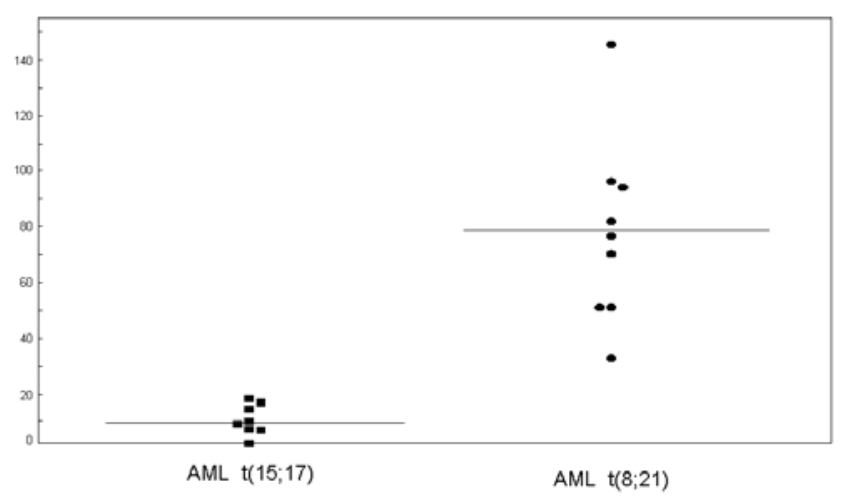

Figure 2. Distribution of the intensity values of a protein peak (10845 Da) of cells with $\mathrm{t}(15 ; 17)$ and $\mathrm{t}(8 ; 21)$. $\mathrm{P}=5.3 \times 10^{-4}$. This peak corresponds well to a protein identified in a previous study as S100A8 (15).

marrow cells after cultivation. As expected, due to the different treatment of the cells, the protein patterns showed significant differences, especially in the lower molecular weight range (Fig. 1). Nevertheless, the intensity and number of detected peaks were similar for both sample sets, demonstrating fixed cells to be adequate for the proteomic analysis of leukemias. The virtual value is based on the fact that numerous samples of these fixed cells are stored untapped in hospitals and institutes worldwide. Additionally, fixed cells seem to be robust and can be stored almost indefinitely, as analyses of 12-year-old fixed cell pellets resulted in spectra of equal quality (data not shown).

Having determined that fixed cells are a valuable source for diagnostics, we analyzed in a proof of principle study whether it is possible to differentiate between subgroups of AML. We chose two subgroups with the cytogenetic translocation $\mathrm{t}(15 ; 17)$ and $\mathrm{t}(8 ; 21)$, respectively. The $\mathrm{t}(15 ; 17)$ translocation was chosen because it is pathognomonic for promyelocytic leukemia (FAB subtype M3) and therefore a well-defined subgroup. The translocation $\mathrm{t}(8 ; 21)$ with blasts mostly in M2 and M1 is also considered a characteristic subgroup of AML. Eight samples with $\mathrm{t}(15 ; 17)$ and 9 samples with $\mathrm{t}(8 ; 21)$, independent of the number of blasts, were analyzed on IMAC protein arrays as described above. Twelve 
protein peaks were found differentially expressed $(\mathrm{P}<0.05)$. One of these peaks, with $\mathrm{P}=5.3 \times 10^{-4}$, is shown in Fig. 2 .

In conclusion, the presented technique allows for the analysis of a small amount of methanol/acetic acid-fixed cells from leukemia patients, which is not possible using standard protocol. We further demonstrated that methanol/acetic acidfixed cells can be used to differentiate between even subgroups of AML. The high sensitivity and the possibility of directly applying fixed cells, lyse and wash are due to the affinity chromatographic chip surface, which allows for the removal of all contaminants. Further studies are necessary to corroborate these results and to confirm that this technique can be useful for retrospective studies leading to proteomic-based diagnostics and therapy for leukemia.

\section{Acknowledgements}

We gratefully acknowledge the support of the German Federal Ministry of Education and Research (BMBF) and the Interdisciplinary Center for Clinical Research (ICCR), Jena, Germany.

\section{References}

1. Sjoholt G, Anensen N, Wergeland L, McCormack E, Bruserud O and Gjertsen BT: Proteomics in acute myelogenous leukaemia (AML): methodological strategies and identification of protein targets for novel antileukaemic therapy. Curr Drug Targets 6: 631-646, 2005.

2. Sjoholt G, Bedringaas SL, Doskeland AP and Gjertsen BT: Proteomic strategies for individualizing therapy of acute myeloid leukemia (AML). Curr Pharm Biotechnol 7: 159-170, 2006.

3. Thadikkaran L, Siegenthaler MA, Crettaz D, Queloz PA, Schneider P and Tissot JD: Recent advances in blood-related proteomics. Proteomics 5: 3019-3034, 2005.

4. Albitar M, Potts SJ, Giles FJ, O'Brien S, Keating M, Thomas D, Clarke C, Jilani I, Aguilar C, Estey E and Kantarjian H: Proteomic-based prediction of clinical behavior in adult acute lymphoblastic leukemia. Cancer 106: 1587-1594, 2006.

5. Balkhi MY, Trivedi AK, Geletu M, Christopeit M, Bohlander SK, Behre HM and Behre G: Proteomics of acute myeloid leukaemia: Cytogenetic risk groups differ specifically in their proteome, interactome and post-translational protein modifications. Oncogene 25: 7041-7058, 2006.
6. Cui JW, Wang J, He K, Jin BF, Wang HX, Li W, Kang LH, $\mathrm{Hu}$ MR, Li HY, Yu M, Shen BF, Wang GJ and Zhang XM: Proteomic analysis of human acute leukemia cells: insight into their classification. Clin Cancer Res 10: 6887-6896, 2004.

7. Hegedus CM, Gunn L, Skibola CF, Zhang L, Shiao R, Fu S, Dalmasso EA, Metayer C, Dahl GV, Buffler PA and Smith MT: Proteomic analysis of childhood leukemia. Leukemia 19: 1713-1718, 2005.

8. Lopez-Pedrera C, Villalba JM, Siendones E, Barbarroja N, Gomez-Diaz C, Rodriguez-Ariza A, Buendia P, Torres A and Velasco F: Proteomic analysis of acute myeloid leukemia: Identification of potential early biomarkers and therapeutic targets. Proteomics 6 (Suppl 1): 293-299, 2006.

9. Engwegen JY, Gast MC, Schellens JH and Beijnen JH: Clinical proteomics: searching for better tumour markers with SELDITOF mass spectrometry. Trends Pharmacol Sci 27: 251-259, 2006.

10. Semmes OJ, Feng Z, Adam BL, Banez LL, Bigbee WL, Campos D, Cazares LH, Chan DW, Grizzle WE, Izbicka E, Kagan J, Malik G, McLerran D, Moul JW, Partin A, Prasanna P, Rosenzweig J, Sokoll LJ, Srivastava S, Srivastava S, Thompson I, Welsh MJ, White N, Winget M, Yasui Y, Zhang Z and Zhu L: Evaluation of serum protein profiling by surface-enhanced laser desorption/ionization time-of-flight mass spectrometry for the detection of prostate cancer: I. Assessment of platform reproducibility. Clin Chem 51: 102-112, 2005.

11. Vorderwulbecke S, Cleverly S, Weinberger SR and Wiesner A: Protein quantification by SELDI-TOF-MS-based ProteinChip System. Nat Methods 2: 393-395, 2005.

12. Driemel O, Murzik U, Escher N, Melle C, Bleul A, Dahse R, Reichert TE, Ernst G and von Eggeling F: Protein profiling of oral brush biopsies: S100A8 and S100A9 can differentiate between normal, premalignant and tumor cells. Proteomics Clin Appl 1: 486-493, 2007.

13. Melle C, Bogumil R, Ernst G, Schimmel B, Bleul A and von Eggeling F: Detection and identification of heat shock protein 10 as a biomarker in colorectal cancer by protein profiling. Proteomics 6: 2600-2608, 2006.

14. Verma RS and Babu A (eds): Human chromosomes: manual of basic techniques. 4th edition. Pergamon Press, New York, pp100-104, 1998.

15. Melle C, Ernst G, Schimmel B, Bleul A, Koscielny S, Wiesner A, Bogumil R, Moller U, Osterloh D, Halbhuber KJ and von Eggeling F: A technical triade for proteomic identification and characterization of cancer biomarkers. Cancer Res 64: 4099-4104, 2004. 